\title{
Evaluating the Performance of Urban Management in Community Sustainable: Case Study in Area of Narmak - Tehran
}

\author{
MOHAMMAD HABIBI ${ }^{1 *}$ and AMIR HOSSEIN POURJOHARI ${ }^{2}$ \\ 1*Department of Urban Planning, Shahr-e-Qods Science and Research Branch, \\ Islamic Azad University, Tehran, Iran. \\ ²Department of Urban Planning, Shahr-e-Qods Branch ,Islamic Azad University, Tehran, Iran.
}

http://dx.doi.org/10.12944/CWE.9.2.29

(Received: April 07, 2014; Accepted: July 08, 2014)

\begin{abstract}
Uncontrolled urban development that was coincided with the Industrial Revolution, make living in a city faced with new problems that were completely antithetical to sustainable development. To solve this problem, administrators, planners, and urban management in general, have prepared plans for development. Because of their unresponsive to urban neighborhoods, development plans and because of their upward to downward processes, these development projects were incapable of solving problems, and many of them have failed. On the other hand, for better urban governance, participation of all actors in both public and private sector and civil society were essential. In addition, on this level of cooperation, leading to ready all actors for culture governance of democratic were realized. This study investigated the role of community-based management in achieving sustainable urban development deals and has analyzed social stability in four dimensions including cultural, economic, physical and environmental. Study area, was a neighborhood of Tehran, in the area of eight, Narmak. The research was a descriptive - analytical study and collecting information and data were performed in the form of documents and survey. The results suggest that the effects of urban management on stabilizing neighborhoods, in physical and environmental aspects, are quite tangible. However, with regard to social and economic dimensions, this effect was more diminished. Certainly, the role and power of urban management in social and economic dimensions could be obtained more sustainability for Narmak neighborhood.
\end{abstract}

Key words: Neighborhood management-centered, Participatory, Sustainable development, Narmak.

\section{INTRODUCTION}

Urban area, with placing the center of the city neighborhoods, as the smallest components inside the city, for achieving optimal management ways of urban communities, are of urban priority programs for the planners. Since, in the division of the city space, urban neighborhoods, are of the smallest organized spaces, so, local communities in cities are the best foci and the workshop of participatory planning and management. Among other categories of institutional, town space, have the most social cohesion. The complexity of urban issues and their importance not only face the planners with the reality of this phenomenon but also have forced them to leave the urban management approach of the previous and deal with fresh ideas and new methods to overcome these issues. Today's, the evolution of urban management and the adoption of new management consist of the affairs of the city for urban sustainable development at the local level (Fanni and Saremi, 2008, pp: 92 and 93). However, in the current era, plan view base on neighborhood planning and neighborhood management, for urban planning is regarded as the predominant approach. In today's society, urban neighborhoods and urban elements fundamental are important link between the city and citizens. From distant past quarters, 
neighborhoods of the cities have special status in formation and organization of municipal affairs. City was formed based on these coherent whole neighborhoods, each neighborhood has different facilities, and equipments needed for its inhabitants, including primary markets, water storage, mosques, baths, etc. Network of way of communication for neighborhood has the hierarchical relationship between different areas (Rahnamayi et al, 2007).

However, rapid spread of urbanization and spread of modernism have left a major effect in changing the structure and function of urban area. Neighborhood traditional system fell apart, and with the institutions of urban management, public management, top-down and centralized management systems, are replaced with the neighborhood management (Rahnamayi et al, 2007). In fact, with the rapid developments in the contemporary era and entering a state of transition, infrastructure of livelihood and social relations stir. In the past, for development management, cleaning and security, and participation were asked from neighborhood residents and in all matters, pertaining to the neighborhood and the role of citizenry was important. However, little by little, this role has been removed from people responsibility and residents were depleted from their special identity of their neighborhood. In such situation, neighborhoods felt themselves apart from city and neighborhood and city problems were managed in absence of citizens. Solving problems related to the neighborhood of Tehran, could lead to a more coherent of neighborhood relations, and in turn, can provide new models of identity construction in the neighborhood. Neighborhoods stability shows their sustainability of the natural and social situation (Shiaa, 2009). Emergences of urban management as an independent concept came to early 1990s in developed countries. The scientific community has considered urban management field as a new discipline in recent decades (Abedi Jafari et al, 2011, p: 180). The establishment of urban management and urban governance authority in terms of cultural and social structure appears based on political, social and cultural structures. City which has the most complicates and variant views of human life, without having urban management discipline that both plans for programs for city development and evaluate the ways for encountering and overcoming the problems will not be useful (Saeednya, 2010, $\mathrm{p}: 19)$. Another approach based on the concept of urban management is local government. Local government is an old entity with a new concept that is rooted in ancient human history and at the time of the introduction of social management of human existence has been established. Self managing is one of the natural needs of the human; in a way that inherently and innately want to participate in his/her affairs of their own destiny (Moghimi, 2003; $\mathrm{p}: 1)$. However, level of local management and administration should be recognized at the national and regional level, followed by, the interface between the two. In fact, today, there is a direct relationship between improving urban management and local decentralization and local democracy has been accepted. Delegation, public participation and institutional context of solving at the lower level, are the success of spatial decentralization policy (Sarafi, 1998, p: 44). In modern urban management system to address the problems and challenges of urban life, several models have been proposed. One of these models is the model that is dominant in urban management, community management model, and is considered regarding dimensions of urban sustainable development. They include "sustainable development", "urban management" and "neighborhoods." Therefore, this study seek to answer the question that, to what extent urban management has been successful in promoting local sustainability indicators to be effective for Narmak.

\section{MATERIALS AND METHODS}

\section{The neccessity of research for the study area}

Urban studies, based on urban neighborhoods, are of the smallest divisions in of system components of the city, in order to achieve optimum management practices for city communities, and are considered as an essential issue for urban planning, and could play an important role in increasing the sustainability and especially empowering of communities. Stability requires decision-making and activities, resulting in capital investment in social capacity to strengthen local, capital, natural, economic or humanity. On the other hand, management in neighborhood-level is a connection link for citizens and urban management. If accepted for city, management, participation 
of all factors influencing on urban development including governmental and city community are necessary. Management in this level is a solution for actors and participating of all people in managing the city will be occurred. Paying attention to the micro-level (neighborhood) is one way of achieving efficient management of urban. Accordingly, it is necessary to pay more attention to the dimensions of the micro-scale and neighborhood-planning program (Karimi and Tavakoli Nia, 2009; Tavakoli and Ostadi Sisi, 2009). Present research because of its nature, was a fundamental survey and the method used was cross - sectional study and field data collection were conducted. The first plate of each lane were randomly selected and used to fill out a questionnaire regarding demographics of the city and neighborhoods using the general formula Cochran, 284 samples were obtained. To assess the reliability of the questionnaire using Cronbach's test, the results of 30 questionnaires have been tested. The alpha values obtained from this test was 0.72 , which indicated good reliability. To obtain validity, the KMO test and Bartlett's sphericity values of 48 questionnaires have been used and the number of 0.7 was obtained which indicated the validity was acceptable. Study on relationship between performance and stability of the Narmak neighborhood and effectiveness of urban management, urban management, regression analysis and analysis of variance (ANOVA) were used (Table 1).

\section{Study area}

Narmak neighborhood with 25,223 inhabitants (based on 2011 census) has been located in eight area of Tehran and is considered as a historical - cultural and main nucleus of the area. It is a residential neighborhood, stable, secure and legible identity that is balance in appropriate link with entire area. Narmak city should be considered of the first planned town with a regular structure of the grid in streets in north - south and hierarchical tendencies (Fig. 1).

\section{Concepts, principles and main elements}

In order to analyze the role of communitybased management in implementing the concept of sustainable urban development in the neighborhood Narmak Tehran, neighborhood-based view of sustainable management has been selected as the predominant view. The neighborhood management, which is the closest level of urban management, has the highest contact with city living of the residents. In fact, in neighborhood management, the main objective was to attract greater participation of citizens in solving local problems in their lives and using the ideas, people skills, capacity and expertise that existed in the neighborhood. In this approach, the neighborhood residents were considered who were able to help urban management in order to identify the most significant problems as well as offer a way to solving them. In the simplest case, the administrator was a connection between local communities and local service providers at a

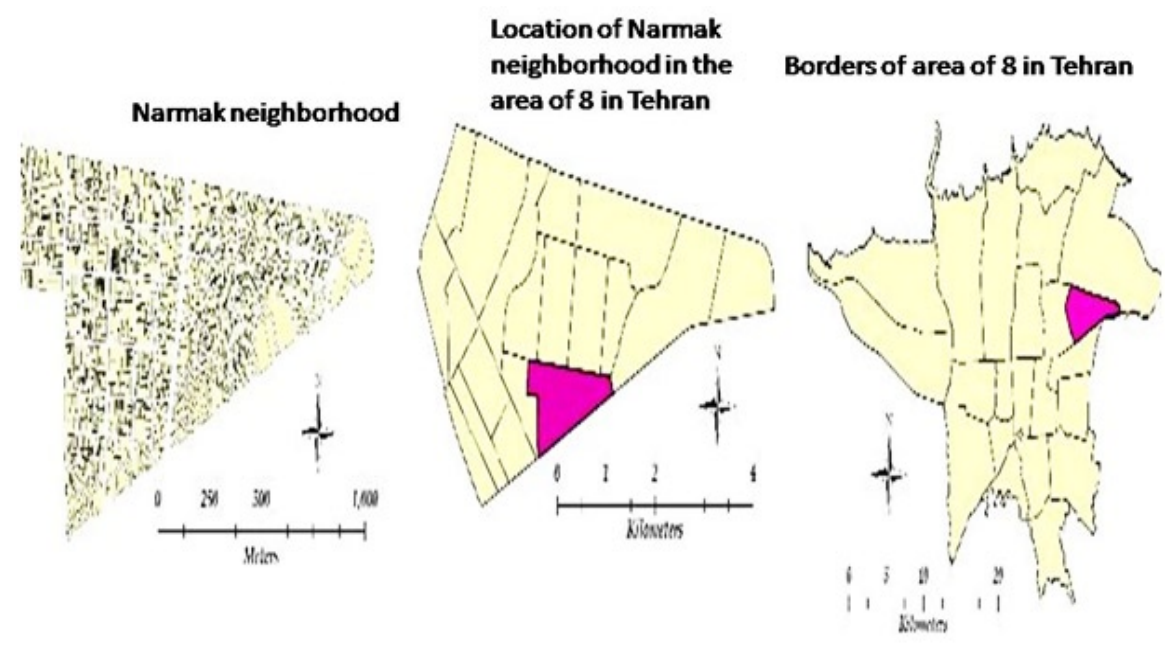

Fig. 1: Location of zone 8 and Narmak neighborhood in Tehran 
local level in order to achieve sustainable urban development.

\section{RESULTS AND DISCUSSION}

To determine the effectiveness of urban management in local stability, linear regression and analysis of variance ANOVA was used. The urban management performance as an independent variable and sustainability as a dependent variable have been considered. Initially, the performances of urban management in Narmak zone have been investigated.

The results showed that presence of significant effects of each dimension of urban

Table. 1: Variables proposed for evaluation of urban management performance

Satisfaction with municipal environmental performance

Satisfaction of the Municipality for socio-cultural function

Satisfaction of the Municipality function in space- physical in the neighborhood
Noise reduction of neighborhood by preventing the creation of places and occupations that are bothering people

Avoidance of placing objects on balconies and beauties of views of buildings and walls Appropriate urban furniture, installing bus stops, installing billboards... Creating shopping centers for buying recyclable waste or increasing separate reservoirs for recyclable waste Waste tank installed in neighborhood streets Cleaning of streets, alleys and water channels Establishment of appropriate population densities and building Creation of infrastructure and communication networks in urban neighborhoods and providing facilities such as street and Trim Construction of parks, green spaces and trees in neighborhoods, good per capita green space Building elements and indicator signs at the neighborhood level Lighting of neighborhood parks and green spaces Construction of pedestrian bridge Creating play areas for children in neighborhood parks Shopping centers, stores and daily markets Reduce congestion of accident-prone location by modifying the main and secondary intersection Creating centers for recreation Cultural programs such as celebration in religious eves and ceremonies A way to create good places to hold ceremonies Construction of cultural and sporting locations such as libraries and sports stadiums and installing equipment in neighborhood parks Construction of a special place for walking and cycling help the people to solve problems through the Council of community Development projects in order to increase comfort and improve the quality of life in neighborhoods

Examination of old texture of neighborhood and more attention to their renewal Installation of alleys names and streets and appropriate homes plating Construction of city landmarks such as construction of entrance name for special buildings or parks in the neighborhood Variation in user services at the neighborhood level for different age and gender groups including women, youth, children Creating equitable access to community services, education, health care, office, on foot, creating equitable access to public transport Construction of Pavement with high quality 
management functions on the neighborhood sustainability $(p<0.05)$. The above table indicates that the environmental performance of urban management had more effect on environmental sustainability, with the index value of 0.56 in comparison to other dimension. By the way, the economic performance of urban management in economic stability with the coefficient of 0.067 showed the least effect (Table 2).

Totally, the performance of urban management in general was the sum of four dimensions (with a significance level of 0.00 and the coefficient determination of R2 of 0.511 had significant effect on the overall stability of Narmak zone (in all dimensions). The following chart based on the estimated curve showed the effect of urban performance on global stability (Fig.2). As can be observed with respect to the coefficient of 0.511 , the overall performance of urban management had high value on the overall stability (Table 3).

\section{Effectiveness of the operational aspects of urban} management in community sustainability

To evaluate the effectiveness of urban management functions dimensions, the overall stability of the neighborhood Narmak, global stability was considered as the dependent variable and each of the functional aspects were considered as independent variables. The overall stability of the neighborhood is shown in the following table (Table 4).

Table. 2: Impact of urban management functions on aspects of Narmak zone stability

\begin{tabular}{lccl}
\hline Significant & $\mathbf{F}$ & $\begin{array}{c}\text { The coefficient of } \\
\text { determination R2 }\end{array}$ & Functional aspects \\
\hline 0.000 & 55.867 & 0.184 & Socio-cultural performance in socio - cultural stability \\
0.000 & 17.925 & 0.067 & Economic performance in economic stability \\
0.000 & 316.146 & 0.560 & Environmental performance on environmental sustainability \\
0.000 & 202.502 & 0.450 & Physical performance in physical stability \\
\hline
\end{tabular}

Table. 3: The effect of urban management performance on the local stability

\begin{tabular}{lcc}
\hline Significant & $\mathbf{F}$ & $\begin{array}{c}\text { The coefficient of } \\
\text { determination R2 }\end{array}$ \\
\hline 0.000 & 258813 & 0.511 \\
\hline
\end{tabular}

Based on physical performance, management and economic performance had the most and least impact on neighborhood stability, respectively. It can be concluded that municipalities had the most activity in physical fields and at the level of local, doing physical activity is more important than other municipal activities.

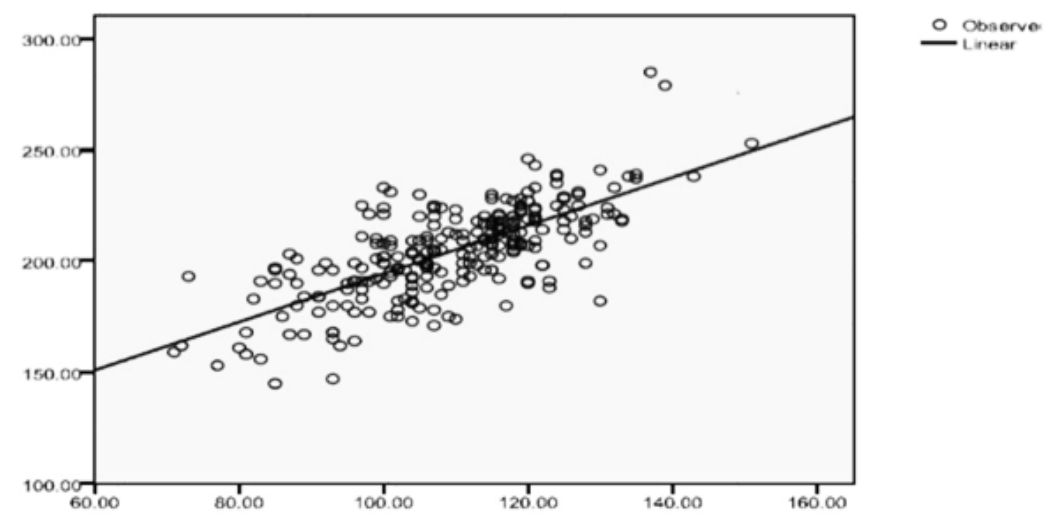

Fig. 2: The effect of urban management on stabilizing of Narmak zone 
Table. 4: Effects of each functional aspects of urban management on the overall stability of the neighborhood

\begin{tabular}{lccc}
\hline significance & Effectiveness & Dimension & priority \\
\hline 0.000 & 0.344 & physical & 1 \\
0.000 & 0.309 & Environmental & 2 \\
0.000 & 0.224 & Socio-cultural & 3 \\
0.001 & 0.063 & Economical & 4 \\
\hline
\end{tabular}

In the case of, effects of functional dimensions of socio-cultural and economic in urban management in sustainability aspects related to urban management, it can be inferred that the municipalities do not take any important responsibilities in these areas therefore cannot have a great effect on the stability related to themselves. Totally, performance of urban management with a determination coefficient of 0.511 , and a significance level of 0.000 had positive effect on the sustainability of local communities of Narmak. Thus, it can be inferred that better urban management can be effective on neighborhood stability. Effectiveness of urban management functions in Narmak neighborhood stability, physical functioning, with $34.4 \%$ had the most effect on the stability of the neighborhood. Then, the effects of other variables were $30.9 \%$, $22.4 \%$, and $6.3 \%$, for environmental, socio-cultural, and economic performance, respectively.

The reason for this could be that based on documents, municipal duties is mostly in the spatial and physical domain and in the next grade the most important tasks were the environmental issues. Finally, the municipal duties were in social, cultural and economical context that not important duties have been defined in these two areas. Therefore, in general it can be inferred that such a responsible task manager, will lead to more stability. For example, physical and environmental functions can be called as such duties. Physical and environmental context in such a way had more effect on the stability of the local neighborhood. The reason for this could be that the trustee Physical and environmental management areas, regions and municipalities have their own neighborhoods. Therefore, based on the defined tasks, management was applied.

However, in the case of economic and social - cultural in cities, municipalities regions, local areas, important tasks were not much undertaken by municipalities and there were not responsible for certain management for them. Multiple agencies with overlapping functions can be seen in this context. Therefore, we cannot expect municipalities that have an impact in these areas. Therefore, it is necessary for having each of the sustainability dimensions, special duty should be defined and responsibility should be done by a special organization and organization should have positive and useful performance.

\section{CONCLUSION}

Following the changes in conditions and factors affecting urban development in recent times, synthetic residential neighborhood have special place in forming of cities. While, sustainable urban development, was a main part of the urbanization literature in recent years, so, paying attention to addressing, and neighborhood development principles and standards still need to research. Perspective of sustainable development, solving of urban problems knew using endogenous formidable forces in urban neighborhoods. Communities and local communities as the social investment have societal position and function, particularly in terms of preservation and development of the metropolitan. Putting together, two theories of sustainable development and the school of environment lead to exploring cultural perspective as a sustainable neighborhood development, respectively (Babcock and Larsen, 1990)

This view reflects the principle that urban areas have enormous social and cultural themes that only the civic culture and recreation areas as the context of the social life of residents lead to giving the local, sustainable development. The identity beside participation, can organize a missing link in our 
community. As long as the person did not remember a sense of belonging, was not being responsible. This lack of responsibility is a major obstacle to the active participation of various civil society of the present city (Rajab Salahi. 2002).

Narmak zone, Tehran can be considered as a sustainable neighborhood that is because of planning product of planners in contemporary period. However, what is regarded as a warning of serious concern is the capacity to tolerate the neighborhood (Barton et al, 2003). Narmak local has reached to a population and building capacity threshold. If continuous monitoring is neglected as a matter of principle, the principles and criteria that have ensured the stability of the neighborhood so far will be lost. Thus, in addition to the usual principles of planning and designing neighborhoods, the neighborhood tolerable capacity should be a primary determinant as a seriously indispensable and considerable for the stability of the neighborhood (Bidgerlulo, 1999).

\section{Suggestions}

\section{Recommendations for metropolitan, Tehran}

1. The elections of metropolitan should be based district council.

2. Strengthen and extend of organizations and neighborhood councils to comply with the City Council and approved sub-councils such as the Council of Adult, Youth Council and Children Council, exercise council and like that in the neighborhood.

3. Encourage and foster of public participation in decision-making and healthy living of neighborhoods and deficiencies of the neighborhood.

4. Reinforcement of social and cultural centers at the neighborhood level through cultural centers and publication, newspapers and weeklies.

5. Community education generalized to different segments of the population in the city and the neighborhood.

6. Director or directors elected from residents of the neighborhood and community trustees.

7. Trust serves residents in the city administrators and local bodies.

\section{Great offers in the area}

1. Equipping the arterial axis of the body to access the important role they play for their neighborhood. Themes such Shahid Madani, Shahid Sani, Janbazan, and Damavand.

2. Diagnosis, classification and making categories, and taping schedule and priorities for the region, especially in the area of old texture, 3.

3. Promotion and strengthening of regional accessibility in the city (highway driven equip, Imam Ali and Damavand mission-driven).

4. Internal and external accessibility of the region and increased permeability.

5. Continuous improvement of living conditions and leisure, work and leisure activities.

\section{Suggestions at the neighborhood level}

1. Increasing social security in the heart of the neighborhood beside police station in addition to the guard quarters and taking responsibility of local people and communities, particularly for women and children.

2. Reinforcement of regional identity by more identifying and manufacture of identity at the neighborhood level.

3. Complete separation of traffic and pedestrians and cars supplied by each of them, while maintaining the highest relevance to transform travel.

4. Lighting for streets and sidewalks, and pedestrian

5. Development of green spaces, sports and leisure.

6. Roadway traffic lubricant development and completion of public facilities in the neighborhood.

7. Culture making for spontaneous participation of neighborhood residents.

8. Development and equipment of Narmak tissue as the tissue samples.

9. Construction of Children's Games places regarding to distance availability.

10. Revenue by collecting and proper segregation of waste by training of local people to achieve this goal.

11. Creating conditions for the leisure time of young people in order to earn money for their residents.

12. Refining, equip and development of local service centers of Narmak located in Nobovat square (Haft- Hoz). 
13. Increasing urban furniture such as mechanized trash that is the location of insertion, but not yet installed.

14. Creating locations for the leisure time of different age groups ranging from a play quarters, library, home, homework etc.

15. Reducing and reforming accident-prone intersection of main and secondary routes.

\section{REFERENCES}

1. Abedi Jafari et al. Constituent component of urban management on the basis of the ten municipalities of the city, Urban Studies, University Dehaghan Journal, 1(I): 202-179 (2011).

2. Babcock, R. Larsen, W.U. Special Districts/ The Ultimate in Neighborhood zoning, Lincoln institute of land policy, Cambridge, M.A (1990).

3. Barton; $\mathrm{H}$, et al : Shaping Neighborhoods: A guide for health, sustainability and vitality", London and New York :spoon press, pp: 35-48 (2003).

4. Bidgerlulo.a.e, : Toward an interactional approach to sustainable community development; Journal of Rural Studies, 15(1): 23-37 (1999).

5. Fanni Zohreh, Saremi Farid. Challenges of neighborhood management system based on sustainable development of metropolitan Tehran, platform, 91-180 (2008).

6. Karimi Sargol, Tavakoli Nia Jamile. The role of micro-and local-scale development in sustainable urban development, Journal of Human Geography, 2(3): 81-92 (2009).

7. Moghimi Seyed Mohammad. The administration of local governments, Tehran: Tehran University and Samt Press (in Persian) (2003).

8. Rahnamayi Mohammed Taqi et al. Structural and functional evolution of the neighborhoods in the cities. Scientific Journal - Research Geographical Society of Iran, a new era, V(12, 13): 19-43 (2007).

9. Rajab Salahi Hossein. Structure of Local Government, Municipal Administration, Planning and Urban Management Program, theoretical and empirical challenges, Tehran: Publications of municipalities (2002).

10. Saeednya Ahmad. Green book series municipalities, city managers, Volume XI, publisher of the country's municipalities (2010).

11. Sarafi Mozafar. Decentralization metropolises in southern states (beliefs and strategies), Architecture and Urban Studies, No. 48, publisher of the country's municipalities (1998).

12. Shiaa Esmaeel. Comparison of Tehran neighborhood with neighborhood criteria for sustainable urban development perspectives, Proceedings of the conference on sustainable development at local, volume 2 , Tehran: a new design (2009).

13. Tavakoli Nia Jamile, Ostadi Sisi Mansour. Stability analysis of neighborhood councils in metropolitan Tehran with emphasis on performance; case study in neighborhood Evin, Darake and Velenjak, Research in Human Geography (in Persian), 70: 29-44 (2009). 